学術論文

\title{
樹脂印刷した木目パターンの触感評価に関する研究
}

\section{Study on Tactile Evaluation for Wood Grain Pattern Created by Resin Printing}

\author{
奥山 $\quad$ 武志 ${ }^{* 1}$ (正員)，高橋 $\quad$ 謙一 ${ }^{* 1}$ ，鈴木 健太 ${ }^{* 2}$ ，西村 進一 ${ }^{* 2}$, \\ 白坂 剛*2, 下村 尚登*2, 田中 真美 ${ }^{* 1}$ (正員)
}

Takeshi OKUYAMA(Mem.), Kenichi TAKAHASHI, Kenta SUZUKI, Shinichi NISHIMURA, Tsuyoshi SHIRASAKA, Naoto SHIMOMURA, Mami TANAKA(Mem.)

In this paper, focusing on tactile imitation of wood using resin-printing, the important factor in tactile imitation is investigated by sensory evaluation and tactile sensor measurement. Some wood imitation samples made by resinprinting the wood grain and wood samples were used in the experiment. First, the surface of wood samples and wood imitation samples were measured by using tactile sensor system by using piezoelectric film as sensory material. The variance of the sensor output and the mean power frequency were calculated as the evaluation parameters of the sensor outputs. Next, sensory evaluation experiments were performed, and wood feeling for each sample are clarified. Finally, by compared among the evaluation parameters obtained from the sensor output and the results of the sensory evaluation. It was found that the variance is an important factor in the tactile imitation of wood.

Keywords: tactile sensation, tactile imitation, wood, sensory evaluation, measurement.

(2020 年 5 月 20 日受付, 2021 年 1 月 13 日再受付)

\section{1 緒言}

近年，製品において見た目や触り心地などの感性的 な機能を向上させるために，様々な加飾処理が施され ている[1,2]。加飾処理の例としては，シボ加工やブラ ス卜加工[3]，樹脂印刷などが挙げられる。このうち， 樹脂印刷は微細な樹脂を積層することでテクスチャを 形成し，触感を伴った印刷物を作製する手法であり， 製品の表面に印刷物を貼り付けることで，製品の表面 を制御することが可能である。さらに，樹脂印刷を用 いて別の素材の触感を付与寸る技術の開発も行われて いる。例えば，木材の触感模倣では，Fig. 1 に示寸よう に木目のパターンを樹脂印刷することで，木材の触感 を表現する技術がすでに利用されている。しかしなが ら，これらの触感模倣物の表面性状とヒトの材質感の 認識との関係は明らかになっていない。

また，これまで触感の評価には主に官能評価が行わ れているが，一般的に官能評価は多くの被験者を必要 と寸ること, 評価者の習熟度や体調によって評価が影 響を受けることなどの問題点がある。また，田中らは 高分子圧電材料の一つであるポリフッ化ビニリデン

(Polyvinylidene diuoride, PVDF) フィルムを受感材

連絡先：奥山 武志，广980-8579 仙台市青葉区荒巻字

青葉 6-6-04, 東北大学大学院工学研究科,

e-mail: okuyama@rose.mech.tohoku.ac.jp

${ }^{* 1}$ 東北大学 ${ }^{*}$ アアルプスアルパイン株式会社

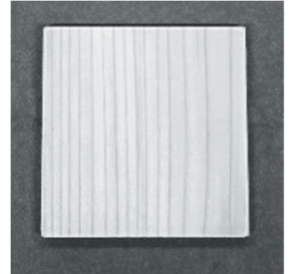

(a) Real wood

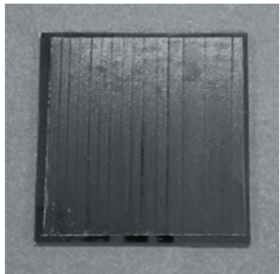

(b) Imitation wood
Fig. 1 Imitation of wood grain pattern.

に用いた触感計測用センサシステムを開発し，布 $[4,5]$ や毛髪[6]を計測対象として実験を行い，本センサシス テムの触感評価への有用性を確認している。

以上に鑑み，本研究では木材および木目パターンを 樹脂印刷した木材を模倣したものを対象物として触感 計測用センサシステムによる計測と，ヒトによる官能 評価実験を行い，センサ出力と官能評価結果の関係を 解析寸ることで定量的な触感評価を行い，木材の触感 模倣において有効な特徵について検討する。

\section{2 計測サンプル}

本研究では計測サンプルとして木材および木目パタ ーンを樹脂印刷した木材を模倣したものを使用する。

木材サンプルは, Fig. 2 に示寸 6 種類（W1～W6）で あり，W1 はハードメープル材，W2～W4 はウォルナ ット材，W5 および W6 は杉材である。 


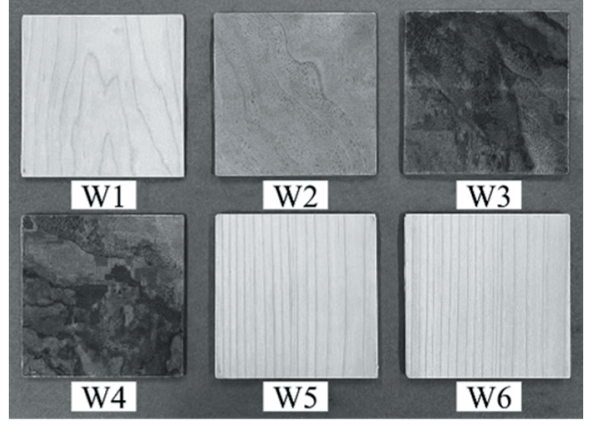

Fig. 2 Wood samples.

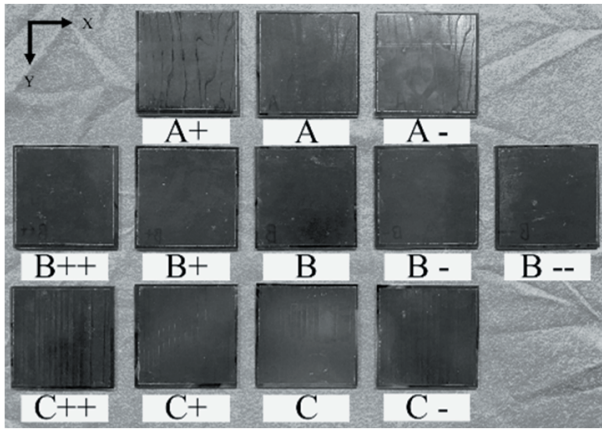

Fig. 3 Wood imitation samples.

模倣サンプルは，木目が樹脂印刷されたフィルムを 同一のプラスチック板に張り付けたものであり, Fig. 3 に示寸 12 種類 $(\mathrm{A}+, \mathrm{A}, \mathrm{A}-, \mathrm{B}++, \mathrm{B}+, \mathrm{B}, \mathrm{B}-, \mathrm{B}--, \mathrm{C}++, \mathrm{C}+$, C, C-)を用意する。模倣サンプルは，基となる木材サン プルの木目を撮影し，画像データから最低明度と最高 明度間を 5 段階に分割し, 明度の高い領域（画像上で 明るく写っている領域）の積層高さが高くなるように 樹脂を積層することで木目の凹凸感を表現している。 模倣サンプルの基となる木材サンプルは, A 系はW1, B 系はW3，C系はW5 である。

さらに各 $\mathrm{A}, \mathrm{B}, \mathrm{C}$ のサンプルで凹凸の度合いを変化 させており, サンプル名の A， B，Cの後付きの+や-な どはその程度を表現している。-- <- < 記号無し $<+<$ ++ の順に積層数およびテクスチャ凸部の急峻度合い が高くなるように作成した。

サンプルの寸法は $100 \mathrm{~mm} \times 100 \mathrm{~mm}$ であり，サンプ ルの座標系は木目を断つ方向を $\mathrm{X}$ 方向, 木目に沿う方 向をY 方向と設定する。また, 各サンプルの表面粗さ のパラメータとして, 算術平均高さ $S a$ を表面形状測 定システム（Polytec,TMS-150）によって計測した。な お, $S a$ は式(1)で表されるように, 基準領域 $A$ における 各測定点の平均面からの高さの差 $z(x, y)$ の絶対值の平 均を表す。

$$
S a=\frac{1}{A} \iint_{A}|z(x, y)| d x d y
$$

Table 1 Surface roughness $S a$ (wood samples).

\begin{tabular}{cc}
\hline & $S a[\mu \mathrm{m}]$ \\
\hline $\mathrm{W} 1$ & 6.64 \\
$\mathrm{~W} 2$ & 9.42 \\
$\mathrm{~W} 3$ & 8.15 \\
$\mathrm{~W} 4$ & 3.85 \\
$\mathrm{~W} 5$ & 5.73 \\
$\mathrm{~W} 6$ & 10.78 \\
\hline
\end{tabular}

Table 2 Surface roughness $S a$ and number of layers (wood imitation samples).

\begin{tabular}{ccc}
\hline & $S a[\mu \mathrm{m}]$ & Number of layers \\
\hline A+ & 1.19 & 6 \\
A & 1.42 & 5 \\
A- & 0.99 & 2 \\
B++ & 1.37 & 6 \\
B+ & 1.84 & 6 \\
B & 1.13 & 5 \\
B- & 1.14 & 5 (Thin print) \\
B-- & 0.61 & 2 \\
C++ & 1.09 & 6 \\
C+ & 1.72 & 6 \\
C & 1.27 & 5 \\
C- & 1.11 & 3 \\
\hline
\end{tabular}

木材サンプルの $S a$ を Table 1 に，模倣サンプルの $S a$ を Table 2 に示す。また，模倣サンプルについては樹脂 印刷の積層数を併記している。木材の方が模倣サンプ ルより Sa は大きいことが確認された。

\section{3 触感計測用センサシステムによる計測実験}

\section{1 触感計測用センサシステム}

Fig. 4 に触感計測用センサシステムの模式図を示す。 本システムは，ステッピングモータで駆動される直動 スライダ装置 (オリエンタルモータ, SPR20B10-3PM, コントローラ : EMP100）に真鎝製のはりを固定し，そ の先端に触感センサを取り付けた構造となっている。 触感センサの受感材には，高分子圧電材料の 1 つであ る PVDF フィルムを用いた。計測対象物は昇降ステー ジに固定されたサンプル固定台上に設置し，昇降ステ

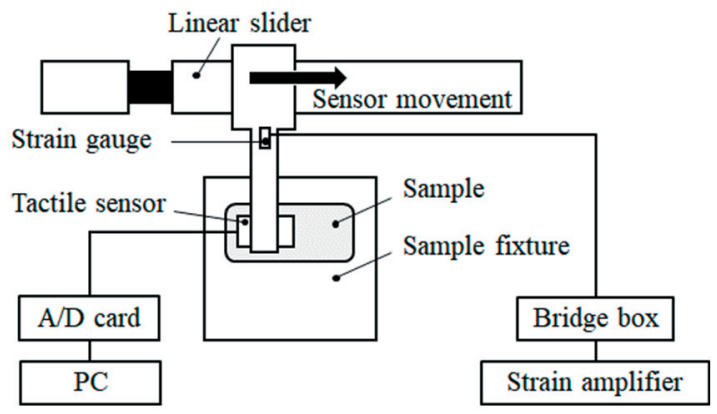

Fig. 4 Schematic of Tactile sensor system. 


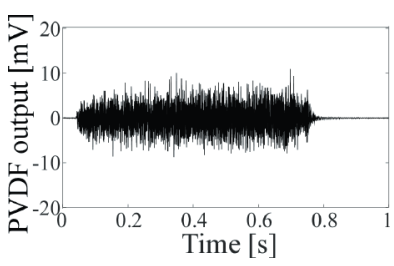

(a) Sample W1,

Scanning direction $\mathrm{X}$

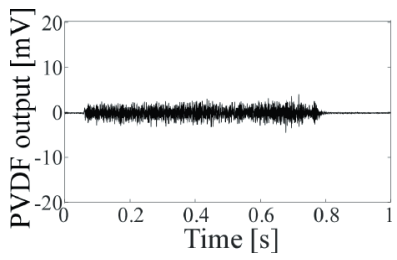

(c) Sample A+,

Scanning direction $\mathrm{X}$

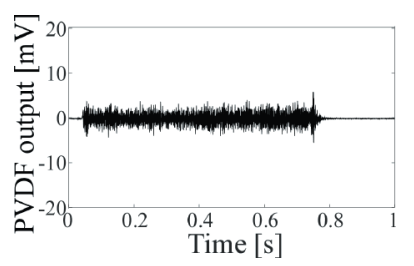

(b) Sample W1, Scanning direction $\mathrm{Y}$

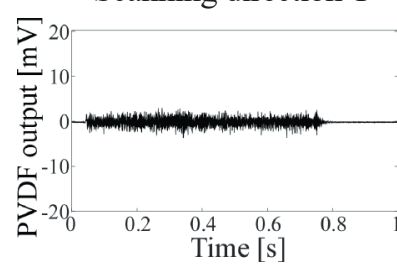

(d) Sample A+,

Scanning direction $\mathrm{Y}$
Fig. 5 Tactile sensor output.

ージを上下させることで初期押付け力を調整する。計 測は，触感センサを計測対象物に初期接触力で接触さ せた後, 直動スライダで走査させ，その時の触感セン

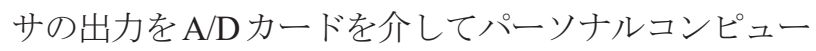
タに保存する。

\section{2 計測条件}

3.1 節に示した触感計測用センサシステムを用いて, 木材サンプル 6 種類, 模倣サンプル 12 種類の計測を 行う。計測条件は, ヒトの動作を参考にいくつかの条 件で予備実験を行い、比較的大きい PVDF 出力が得ら れる条件として, 初期接触力を $0.6 \mathrm{~N}$, 走査速度を 75 $\mathrm{mm} / \mathrm{s}$, 走查距離を $50 \mathrm{~mm}$, サンプリング周波数を $5 \mathrm{kHz}$, 計測時間を 2 秒間に設定した。また, 走査方向はX方 向, Y 方向の 2 方向とし, 各 5 試行ずつ計測を行う。

\section{3 計測結果}

触感センサのセンサ出力の一例として，木材サンプ ル $\mathrm{W} 1$, 模倣サンプル $\mathrm{A}+$ の $\mathrm{X}, \mathrm{Y}$ 各走査方向の計測結 果を Fig. 5 に示す。材質間で比較すると，模倣サンプ ルに対して木材サンプルの振幅が大きいことが確認さ れた。また, 走査方向で比較すると, 木材サンプルで は X 方向に走査したときの振幅が $\mathrm{Y}$ 方向に走査した ときの振幅と比較して大きく, 走査方向による振幅の 差異が確認された。

次に, 得られた出力波形に対して周波数解析を行い, パワースペクトル密度(Power spectrum density, PSD)分 布を求めた。PSD 分布の一例として, 木材サンプル W1, 模倣サンプル $\mathrm{A}+$ +各走査方向についての PSD 分布を

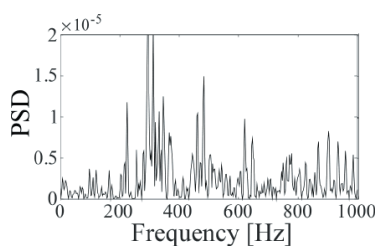

(a) Sample W1, Scanning direction $\mathrm{X}$

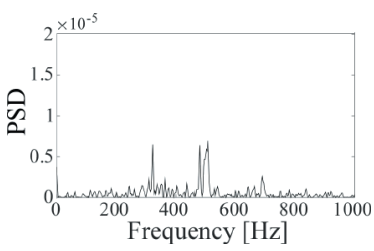

(c) Sample A+,

Scanning direction $\mathrm{X}$

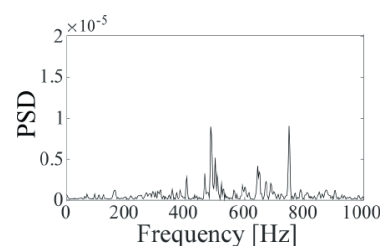

(b) Sample W1,

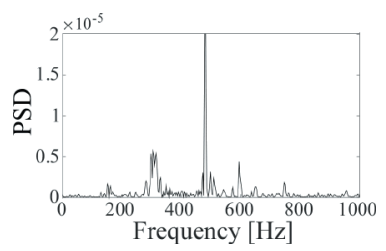

(d) Sample A+, Fig. 6 Power spectrum density.

Fig. 6 に示す。Fig. 6 を見ると，材質および走査方向に よって分布形状やピーク值の大きさが異なることが確 認された。

これらの結果を基に，センサ出力の振幅および周波 数特性を詳細に解析するために評価パラメータを算出 する。

\section{4 評価パラメータ}

計測結果から，材質および走査方向でセンサ出力の 振幅に差異が確認された。そこで，振幅の特徵を評価 するために, センサ出力の分散值 Var を式(2)を用いて 求める。

$$
\operatorname{Var}=\frac{1}{N-1} \sum_{i=1}^{N}\left(x_{i}-\bar{x}\right)^{2}
$$

ここで, $N$ はデータ数, $x_{\mathrm{i}}$ は $i$ 番目のデータ, $\bar{x}$ は計 測データの平均值である。サンプルおよび走査方向ご とに 5 試行分の分散值の平均值を算出した。

Fig. 7 に木材サンプルの分散值の平均值, Fig. 8 に模 倣サンプルの分散值の平均值を示す。材質間で比較す ると，模倣サンプルの分散值に対して木材サンプルの 分散值が大きく，材質間で大きな差異が確認された。 一方，模倣サンプル内で比較すると，積層数の多いサ ンプルで分散值が大きくなる傾向が確認された。

また，走査方向で比較すると，木材サンプルでは X 方向に走査したときの分散值がY方向に走査したとき の分散值と比較して大きく，走査方向による差異が確 認された。この要因として, サンプルの座標系は木目 を断つ方向を $\mathrm{X}$ 方向，木目に沿う方向を $\mathrm{Y}$ 方向とし 


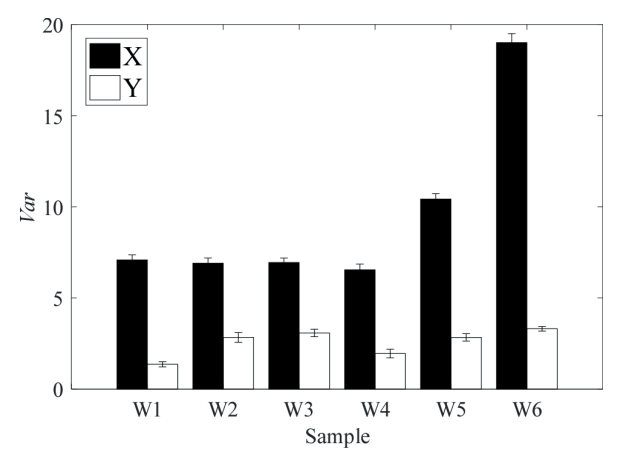

Fig. 7 Comparison of variance in wood samples.

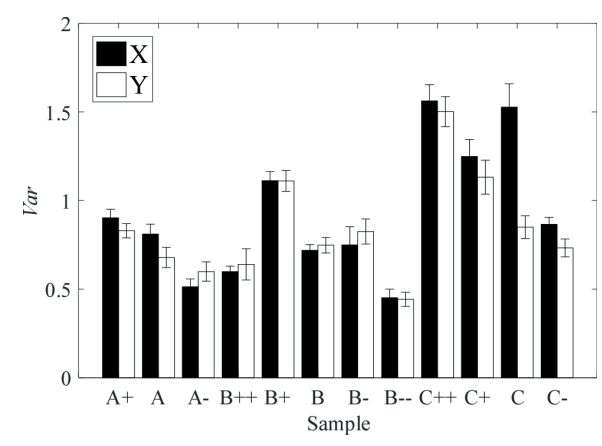

Fig. 8 Comparison of variance in imitation samples.

て設定しているため，木材サンプルでは木目が影響し たことで走査方向による分散值の差異が生じたと考え られる。一方で, 模倣サンプルでは走査方向による分 散值の差異は確認されなかった。この要因として, 模 倣サンプルでは出力が小さいために木目による影響が 現れにくかったことが考えられる。

周波数解析によって得られた特徵を詳細に解析寸 るために，重心周波数 $M P F$ を次式で算出する。

$$
M P F=\frac{\sum_{i=10}^{400} f_{i} \cdot \operatorname{PSD}\left(f_{i}\right)}{\sum_{j=10}^{400} \operatorname{PSD}\left(f_{j}\right)}
$$

ここで, $P S D\left(f_{i}\right)$ は $f_{i}[\mathrm{~Hz}]$ における PSD 值である。な お, 求める周波数帯はヒトの振動を知覚する触覚受容 器であるパチニ小体とマイスナー小体の反応域を参考 にし，10 400 Hz とした。サンプル及び走査方向ごと に 5 試行分の重心周波数の平均值を算出寸る。

Fig. 9 と Fig. 10 に木材サンプルとの模倣サンプルの 重心周波数の平均值をそれぞれ示す。Fig. 9 にあるよ うに木材サンプルでは, 重心周波数が $250 \sim 280 \mathrm{~Hz}$ 付 近であることが確認された。一方，Fig. 10 に示寸模倣 サンプルの重心周波数は, C 系のサンプルについては 積層数や方向による差異が大きいが, $\mathrm{A}$ 系, $\mathrm{B}$ 系のサ

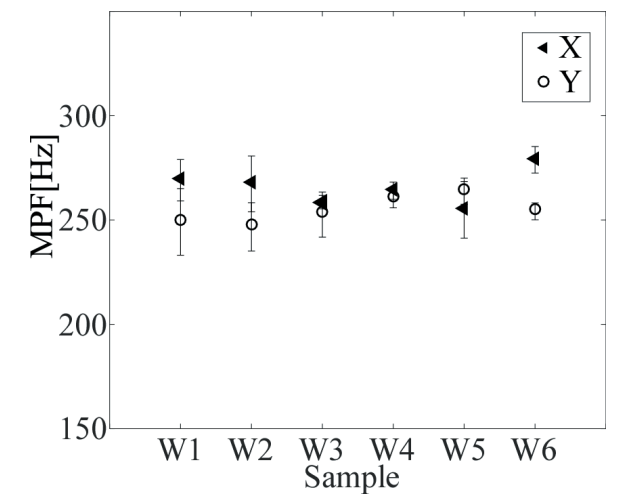

Fig. 9 Comparison of $M P F$ in wood samples.

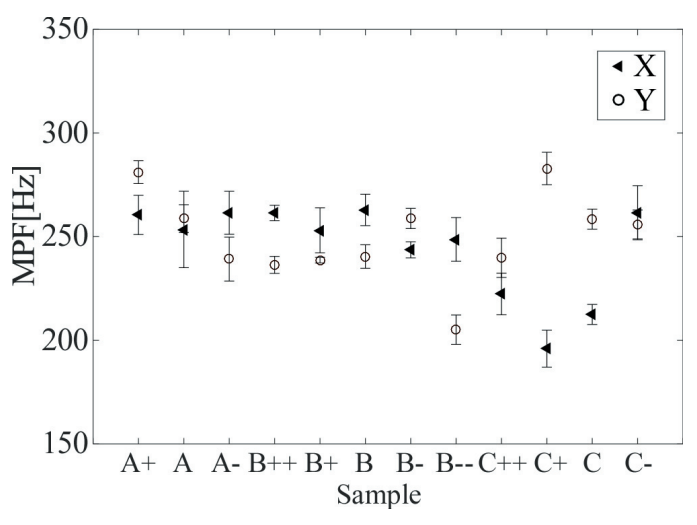

Fig. 10 Comparison of $M P F$ in imitation samples.

ンプルでは木材サンプルと同程度の周波数帯域に分布 していることが分かる。以上より，重心周波数はほぼ 再現できていることが確認された。

\section{4 官能評価実験}

\section{1 実験方法}

模倣サンプルの触感が木の触感のように感じるか の木材感を調査するために, 「木のように感じる/木の ように感じない」を評価項目として官能評価を行う。 被験者は 22 25 歳 (平均 23.2 歳) の男性 5 名であり, それぞれを被験者 $\mathrm{A} \sim \mathrm{E}$ と呼称する。本実験では, 模 倣サンプルのみを提示した場合と，模倣サンプルと木 材サンプルを混合して提示した場合についてそれぞれ 評価を行う。

模倣サンプルについては，触感計測用センサシステ ムの計測結果から， $\mathrm{A}$ 系， B 系，C 系においてそれぞ れ大きな分散值を示した $\mathrm{A}+, \mathrm{B}+, \mathrm{C}++$ を用いることと する。さらに，模倣サンプルのみの官能評価の場合に はこれらに，凹凸度合いがそれぞれの 2 段階下にあた る A-, B-, C を加え, 6 種類のサンプル (A+, A-, B+, B-, C++, C) とした。また, 模倣サンプルと木材サン プルを混合した官能評価では模倣サンプルを作製する 


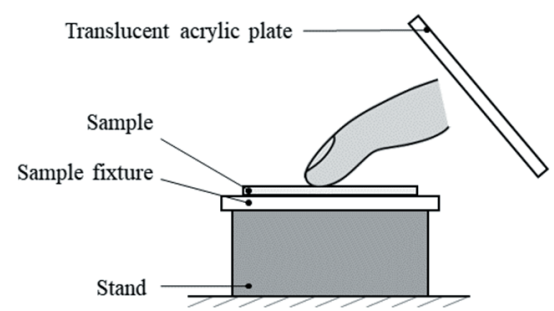

Fig. 11 Measurement system for sensory evaluation.

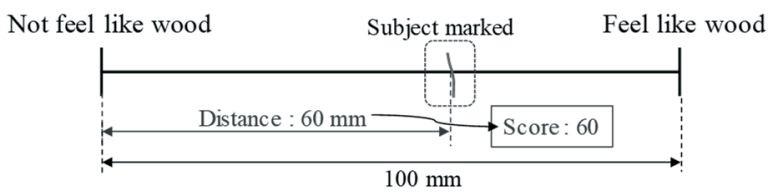

Fig. 12 Question sheet of visual analogue scale.

際に基にした木材サンプル 3 種類 W1，W3，W5 を加 え, 6 種類のサンプル $(\mathrm{A}+, \mathrm{B}+, \mathrm{C}++, \mathrm{W} 1, \mathrm{~W} 3, \mathrm{~W} 5)$ とする。

本実験に用いた実験装置を Fig. 11 に示す。本装置で は，スタンド上に取り付けられたサンプル固定具に計 測サンプルをはめ込むことで固定している。また，実 験時はサンプルと被験者との間に半透明のアクリル板 を配置することで視覚情報を遮断している。

評価方法には，視覚的評価スケール (Visual analogue scale，VAS）法[7]を用いた。VAS 法は質問項目に対す る主観的な程度を $100 \mathrm{~mm}$ の線分上に印を付けること によって評価する方法である。本実験に用いたアンケ 一ト用紙とその回答例を Fig. 12 に示寸。アンケート用 紙には $100 \mathrm{~mm}$ の線分が描かれており, 線分の左端に は「木のように感じない」, 線分の右端には「木のよう に感じる」と書かれている。被験者はサンプルの評価 として適切だと思われる位置に印を付けることで評価 を回答する。解析では, 被験者が付けた印と線分の左 端との距離を計測し, 距離 $1 \mathrm{~mm}$ に対して評価值を 1 とした。Fig. 12 の回答例では, 被験者が付けた印から 左端までの距離が $60 \mathrm{~mm}$ であるため, 評価值は 60 と である。したがって, 評価值は $0 \sim 100$ の範囲であり, 值が大きいほど被験者は木のように感じていると評価 できる。

被験者は，1 つ目のサンプルについて利き手示指で 自由に触れて評価を行い, アンケート用紙に描かれた 線分上に印を付けることで評価を回答する。これをサ ンプル 6 種類 $\times 3$ 試行=計 18 回評価を行う。なお, 各 サンプルについて 3 試行ずつ評価したうち，解析には 2 試行目と 3 試行目の結果を平均して用いた。

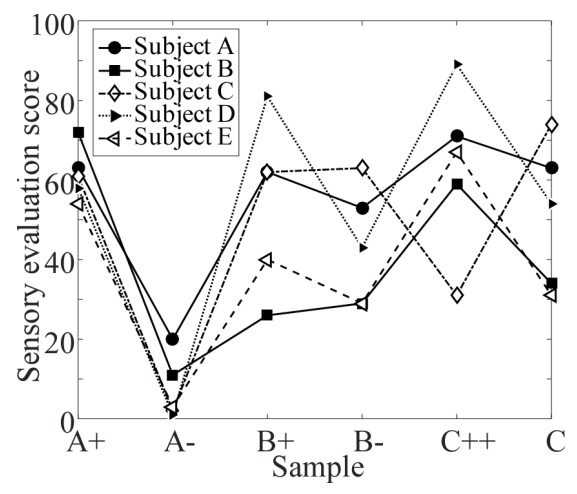

Fig. 13 Sensory evaluation result for wood feeling in imitation samples.

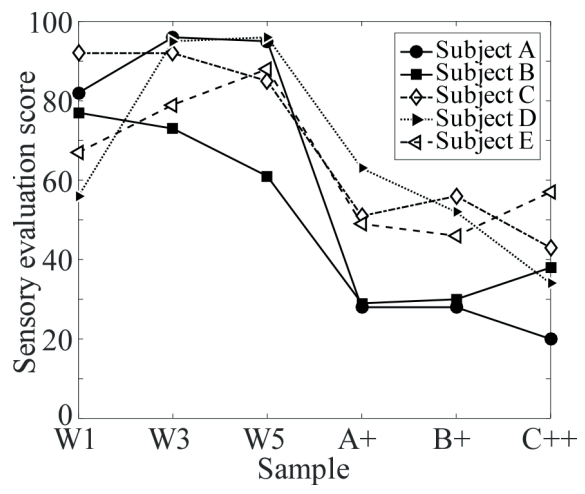

Fig. 14 Sensory evaluation result for wood feeling in imitation samples and wood samples.

\section{2 実験結果}

模倣サンプルのみの官能評価結果と模倣サンプル と木材サンプルを混合した場合の官能評価結果をそれ ぞれ Fig. 13， Fig. 14 に示す。各グラフは横軸がサン プル, 縦軸が 2, 3 試行目の評価值の平均值であり, 全 被験者分の官能評価結果を示している。

Fig. 13 に示寸模倣サンプルのみを提示した場合では, $\mathrm{A}$ 系， $\mathrm{B}$ 系， $\mathrm{C}$ 系それぞれにおいて積層数の多い $\mathrm{A}+$, B+, C++の評価值が高く, 比較的木のように感じてい ることが分かる。したがって, 模倣サンプルでは積層 数を増すことで木材感が強くなることが確認できた。

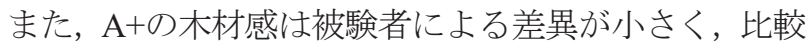
的評価值が大きいことから，多くの被験者が木材の触 感を連想するような木目パターンであると考えられる。

一方で，Fig. 14 に示寸木材サンプルと模倣サンプル を混合して提示した場合では，木材サンプルの評価值 に対して模倣サンプルの評価值が低かった。この結果 から，木材と比較できる環境下では，被験者は模倣サ ンプルと木材サンプルの触感の差異を大きく感じ取り， 模倣サンプルに対する木材感が低く評価されることが 分かった。 


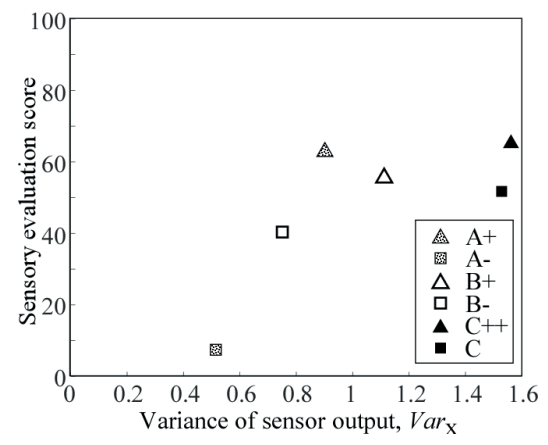

Fig. 15 Relationship between $\operatorname{Var}_{x}$ and sensory evaluation score for wood feeling in wood samples.

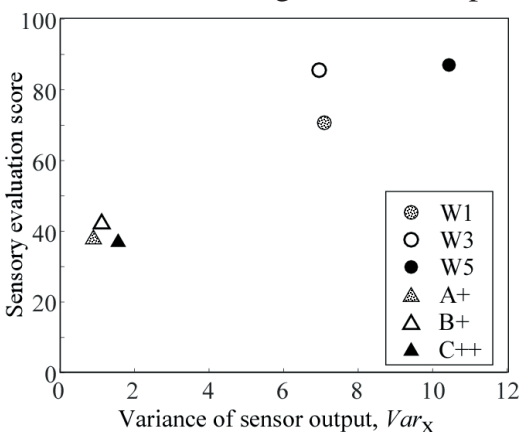

Fig. 16 Relationship between $\operatorname{Var}_{x}$ and sensory evaluation score for wood feeling in wood samples and imitation samples.

Table 3 Correlation coefficient between evaluation parameter and sensory evaluation score for wood feeling.

\begin{tabular}{ccccc}
\hline & $\operatorname{Var}_{x}$ & $\operatorname{Var}_{y}$ & $M P F_{x}$ & $M P F_{y}$ \\
\hline Imitation & 0.728 & 0.705 & -0.406 & 0.345 \\
Wood and Imitation & 0.957 & 0.866 & 0.472 & 0.090 \\
\hline
\end{tabular}

\section{5 触感計測用センサシステムによる計測結果と 官能評価結果の関係}

触感計測用センサシステムによる計測結果から算出 した評価パラメータと，木材感についての官能評価結 果の関係を考察する。

評価パラメータと官能評価結果の関係の一例とし て, 模倣サンプルのみの官能評価值と X 万方に走査し たときの分散值の関係，模倣サンプルと木材サンプル を混合させたときの官能評価值とX方向に走査したと きの分散值の関係をそれぞれ, Fig. 15, Fig. 16 に示す。 なお，各グラフにおいて横軸は 5 試行分の分散值の平 均值, 縦軸は全被験者の評価值の平均值を示している。 Fig. 15, Fig. 16 の結果より, 分散值が大きくなるほど 評価值が大きくなる傾向が確認された。

さらに，評価パラメータと評価值の関係を詳細に見 るために，全評価パラメータと木材感の評価值との間
の相関係数を Table 3 に示す。Table 3 を見ると, 模倣 サンプルのみの官能評価結果，模倣サンプルと木材サ ンプルを混合した官能評価の両場合で，木材感の評価 值と X,Y両走査方向の分散值との間で強い相関関係が あること確認された。

以上の結果から，木材感の評価においてセンサ出力 から求めた分散值が重要なパラメータであることが考 えられる。また，触感計測用センサシステムによる計 測結果から模倣サンプルの積層数が多いほど分散值が 大きくなる傾向であること，官能評価結果から模倣サ ンプルの積層数が多いほど木材感が高く評価されるこ とを考慮すると，模倣サンプルの積層数を増やし分散 值を木材サンプルの值に近づけることでより木のよう な触感に近づけられる可能性が示唆された。

\section{6 結言}

本研究では，本研究では木材サンプルおよび木材の 木目パターンを樹脂印刷した模倣サンプルに対して触 感計測用センサシステムによる計測と，ヒトによる木 材感に対する官能評価実験を行った。相互の関係から, 触感計測用センサシステムによる計測結果から算出し た分散值と木材感が関係していることを明らかにした。 また，模倣サンプルの積層数が多いほど分散值が大き くなる傾向があることから，木のような触感を得るた めには，樹脂印刷の積層数を増やし分散值を大きくす ること有効であることが示唆された。

\section{参考文献}

[1] 川堰宣隆, 精密切削加工を利用したプラスチック成形品 の触感制御とその評価, 精密工学会誌, Vol. 82, No. 11, pp. 948-951, 2016.

[2] 秋元英郎，プラスチックの加飾技術，表面技術，Vol.67， No.5, pp.232-236, 2016.

[3] 相澤淳平, 平出真一郎, 北野哲彦, 樫山岡士，他，樹脂 表面テクスチャにおける触感・外観の感性評価, 長野県 工業技術総合センター研究報告, No.9, pp.17-21, 2014.

[4] M. Tanaka, Measurement and valuation of touch sensation (Texture measurement on underclothes), JSAEM Studies in Applied Electromagnetics and Mechanics, Vol.12, pp.53-58, 2002.

[5] 小林秀光, 田中真美, 触覚感性計測用センサシステムの 開発に関する研究，日本機械学会, 2007 年度年次大会講 演論文集, pp.333-334, 2007.

[6] T. Okuyama, M. Hariu, T. Kawasoe, M. Kakizawa, et al., Development of tactile sensor for measuring hair touch feeling, Microsystem Technologies, Vol.17(5-7), pp.1153-1160, 2011.

[7] 山下利之, 人間工学のための計測手法, 人間工学, Vol.51, No.4, pp.226-233, 2015. 